\title{
Wearable Technology: Facilitating or Complexing Education?
}

\author{
Belsam Attallah and Zakea Ilagure
}

\begin{abstract}
The application of wearable technology in education is an expanding area of interest to both educators and researchers in this field. Fundamental factors like students' interactivity and engagement with their learning have found to be easily achieved when effectively utilizing this emerging technology by academic institutions. This paper focuses on investigating recent applications of this evolving technology in the education field (within the last three years), and highlighting the limitations and obstacles accompanying these applications. The paper discussed the affordances of wearable technology in education and the negative aftereffects in order to judge how effective its employment is in enhancing students' learning and achievement in their studies. The paper concluded that there is a considerable number of restrictions that educators, and producers of this technology, should take into account before proposing further implementation of wearable devices in learning and teaching.
\end{abstract}

Index Terms-Education, educational technology, learning, learning technology, teaching, wearable computing, wearable devices, wearable technology, wearables.

\section{INTRODUCTION}

The application of wearable technology in education is rapidly increasing over the past few years. Recent research demonstrated that wearable computing can be utilized by educators to improve the quality of, and facilitate, their delivery, while it could also be used by students to enhance the way they receive course syllabus, and their interaction and engagement with the curriculum. By using this technology, educators aim at improving students' achievement in their studies and their learning experience. "The increased use of mobiles has created an opening for other sorts of devices to enter the classroom" [1].

Statistics on the production of wearable devices shows that around 13 million wearable devices were shipped to consumers in 2013 , and that this number is anticipated to rise to 170 million by 2018 [2]. "Forrester Research reports that more than $20 \%$ of Internet-connected adults regularly use a wearable device" [1]. Such a tremendous growth reinforces the fact that educators, amongst other specialists, should consider the impacts of this technology on education/higher education and the learning experience of students.

Alongside a number of advantages, the employment of wearable technology in education is accompanied by a number of limitations and disadvantages. This research paper

Manuscript received September 12, 2017; revised November 24, 2017.

The authors are with Computer Information Science (CIS), Higher Colleges of Technology (HCT), UAE (e-mail: belsam.attallah@yahoo.com, zakiazi@hotmail.com). investigates the different factors associated with the application of this technology in the education field.

\section{The APPLICATION OF WEARABLE TEChNOLOGY IN LEARNING AND TEACHING}

"Wearable technology is a kind of technology that is worn by a user which is used in obtaining specific information" [3]. This emerging technology provides students with a different information sharing experience related to the way the course material videos and audios are presented [3]. The wearable devices, which are believed to have educational use are: Google Glass, Muse, Virtual Reality and GoPro cameras [2]. The majority of references which provided definitions of wearable technology, focused on the aspect of information capturing and sharing. "Wearable technologies can be defined as wearable digital devices that often incorporate wireless connectivity for the purposes of seamlessly accessing and exchanging contextually relevant information" [4].

Wearable Computing is a hands-free technology. This aspect is very important for students, as freeing-up their hands while remaining connected to the device's functionality enables freedom to move in the educational space and interaction with the real environment [5]. In addition, the hands-free access to information and knowledge supported by wearable devices inspires a new era of mobile learning design [6].

Innovations in wearable technology renovated the learning and teaching process, where students deal with their studies in a more constructive, active, and self-directed way. Wearable technology enables opportunities for students to understand more quickly and access information with less mental input or actions. It is important to consider that utilizing wearable technology in education is totally different from the traditional learning methods, where students must attend classes at a fixed time and location. However, educators need to learn how to effectively employ wearable computing in an educational environment [7].

Reference [4] investigated the feasibility of applying wearable technologies in tertiary education contexts. Their study involved 202 university educators and concluded that there is usefulness in utilizing wearable computing for learning and teaching. However, the participants were not very enthusiastic about the feasibility of using four different wearable devices suggested by the researchers in their classes. "Importantly, participants on average provided a significantly lower feasibility rating as compared to utility for the four use cases that were deemed to be of most value" [4].

The new generation of pedagogical theories and 
curriculum design for mobile education presents teachers with new opportunities and combinations of educational possibilities for wearable technologies [8]. The reference clarified that there are many researchers investigating the application and development of wearable devices in a number of fields other than education, while there is much less literature into the application of this technology in education. Yet, they indicated a number of examples on the use of wearable devices in higher education, such as the University of South Wales uses virtual reality (VR) head-mounted displays in engineering, and the University of Western Australia uses Fitbits in their Self eHealth Challenge. They confirmed that employing this technology in higher education resulted in "students feeling a deeper connection with events and people..., deeper student analysis and understanding of scenario-based practices..., and seamless integration into student learning workflows" [8].

Devices such as 'Google Glass', which is considered "the most important tool utilized in education", enable remote students to watch and listen to the lecture in the university without physical presence, e.g. students of the medical field watching a surgeon lecturer doing a surgery in real time [3]. Google Glass also enables students to receive text messages and alerts related to different aspects of their studies, e.g. assessment deadlines and notifications by their lecturer. It also "provides quantitative data relating to attention and focus", and "answer/translate questions in a foreign language" [2]. This wearable device also allows educators and students to stay connected to an interactive environment, where teachers can benefit from the facial recognition facility to generate a 'Student Information System' and take attendance [9]. Just by looking at individual students, teachers will get access to their records with details on their academic and non-academic performance and attendance rate. Such information could also be used to generate students' reports, class timings, and schedules for students [9].

Virtual reality, such as Oculus Rift, has other noticeable impacts in education. It allows learners to experience learning differently and without the risk involved. It provides live scenarios for students and takes them to places that are either difficult, or sometimes impossible, to access in real-life, e.g. space studies, archeology courses, medical education, chemical engineering and aviation training. The utilization of virtual reality wearables in education enables hands-on, engaged and interactive participation of students in their learning process compared to the passive way of reading/watching lessons in a traditional classroom [10]. Oculus Rift is a wearable Head Mounted Display (HMD), which is a comfortable to wear, and light-weighted, stereoscopic display with ultra wide field of view (100 degree) that creates the immersion needed to experience virtual reality. It is also provided on affordable prices [10].

Google Expeditions is another virtual reality wearable device that is used in education. It provides a unique classroom experience via enabling educators to accompany their students on guided virtual field trips. The device provides more than 200 different expeditions to places like museums, underwater and outer space, where students immerse in a 360-degree experience that enables them to explore some incredible locations [11]. "Expeditions are collections of linked virtual reality (VR) content and supporting materials that can be used alongside existing curriculum" [12]. Both 'Augmented Reality' and 'Virtual Reality' present persuasive applications for higher education, as their devices are designed to transfer learners to "any imaginable location across the known universe and transforming the delivery of knowledge and empowering students to engage in deep learning" [1].

The wearable device that is utilized to record a lecture or students' performance on a tasks is GoPro camera. This device facilitates, and documents, lecturers' observation of the learning environment and their evaluation of students' performance. "GoPro camera is a wearable digital camera that can record action experiences and provide possibilities to capture embodied, sensory, kinesthetic and emotional knowledge and skills" [13].

Muse is a brain sensing headband that measures brain activity, and generating data which is sent to a tablet or a smartphone using an embedded wireless connection. It is used to support the learning process of students by determining what keeps them focused [2]. "The Muse headset incorporates EEG sensors into a headband to monitor cognitive states of focus and distraction as an aid to meditation" [5]. Educators could obtain valuable data on their students using this wearable device during the lesson via monitoring level of engagement and cognitive focus.

Other wearable devices applied in education are smart jewelry/watches, which for example, are able to send notifications to both lecturers and students if situations in a laboratory become dangerous. A smart bracelet could be utilized to measure hydration levels, distance walked (in steps) and heart and breathing rates. The data is transferred by the bracelet to a tablet (or a smart phone), where the lecturer can monitor students' physical activities and ensure that they achieve their targets while remaining safe [2]. The smart watch is considered the most precise information displaying device in education, and it has "an extremely simple and a wonderful system that lets the students send messages to their teachers if they are too shy to ask out loud" [14]. Smart watches are increasingly becoming popular amongst people being more productive and convenient alternatives to smartphones [1].

Wearable technology could be utilized to help students with illness, disabilities and/or learning difficulties, e.g. to monitor autistic students and send alerts when certain situations happen, which increases their safety within academic settings [2]. Another example is diabetic students, who "can utilize wearable technology to better manage their medical condition so missed class time is reduced" [2]. Research showed that disabled students benefit hugely from the many advantages that the application of wearable technology brings to their education, as it makes their learning process easier and enables them to compensate their handicap. "Students with vision or attention issues are able to participate in class undisturbed, or using bone conduction together with smart glass device could help students with hearing loss" [15].

\section{LIMITATIONS OF WEARABLE TECHNOLOGY IN EDUCATION}


An important limitation to the use of wearable computing in education is overreliance on technology [6]. Some educators believe that the continuous use of wearable devices by students make them dependent on this technology, hence obstructing independent thinking. Students might become reliant on wearable devices to give them answers and/or decisions on what to do next, which reduces their ability to think critically [6].

In discussing the restrictions associated with utilizing Google Glass for educational purposes, the lecturer is required to wear the Glass throughout the lecture time, and upload the course material alongside the recording of the session to the internet [3]. Although the students can directly access the online material submitted by their lecturer, who will interact with them online, this process requires continuous and stable access to the internet at all times (for the type of material shared), and also demands a certain level of computing skills by both the lecturer and students to achieve this. Another limitation is possible distraction to students, which is considered much higher than that caused by using smart phones, in addition to certain invasion of privacy issues [9]. Moreover, "prolonged usage of Google Glass can cause health issues mainly damaging eyesight", and the excessive use of on-the-go social media applications may harm the user's personal life [9]. In the same regard, many educators believe that wearable technologies negatively impact the quality of learning acquired by students due to the distraction the wearable devices cause and the facility they provide for students to view non-subject related material at any time, resulting in not being engaged in their learning [6]. This makes it harder for educators to monitor and manage students' attitude towards their learning.

With regards to the ability to share/transfer information, wearable devices' capacity to instantly transmit and receive data presents a number of concerns related to privacy, social, and ethical issues [16]. Moreover, the ICT infrastructure must be addressed, as it plays a vital role in ensuring an uninterrupted and widespread internet that is needed for an effective running of wearable devices in educational institutions. These issues, alongside possible students' distraction while using wearable devices especially in large overcrowded classrooms, raise a significant concern regarding the feasibility of using this technology in the education sector [16].

In addition to the above, wearable devices are rather small and light, and they do not usually have their own wireless internet connection; instead, they need a smart phone or a computer to connect to the internet [17]. Therefore, "the wearable is, with some exceptions, essentially useless without a smart phone connection" [17]. This could be an obstacle facing an effective application of this technology in education, as although the majority of today's students carry their smart mobile phones with them at all times, not every student's smart phone will have the type and quality of internet service required for the above highlighted information sharing. In addition, students running various wearable applications on their smart phones are expected to drain their batteries very quickly. Also, certain wearable devices will demand their own larger battery capacity to cope with heavy use, e.g. a full-day use of Google Glass requires re-charging of the Glass in mid-day [17]. Many educators felt that using wearable devices in education is likely to be accompanied with technical problems, which limits their usage, e.g. network connectivity and battery life [6].

One of the reasons behind the under-utilization of wearable technology by educators in tertiary education is they do not believe that the application of this technology in learning and teaching has sufficient pedagogical value [4]. The other possible reason, the reference added, is that educators consider the implementation of wearable computing in their classes as not feasible. Other obstacles highlighted by the reference were: technological issues, the cost of wearable devices, possible distraction to students, privacy concerns and resistance to change. It is crucial for educators to first develop a good understanding of the affordances of wearable technologies in education in order for them to utilize their pedagogical opportunities for an effective implementation in learning and teaching [6].

In the same regard, there are three challenges related to addressing pedagogical practice and theories when using virtual reality wearable devices in education. These are: cost, usability and fear of technology [10]. Another important factor associated with the use of virtual reality in education is students' attitude towards this technology and their readiness to incorporate it in their learning. The reference added that in some HMD devices, such as Google Cardboard, which incorporate a smartphone, the head tracking is achieved using the built-in accelerometer of the phone, which causes lag, motion sickness and/or headaches for many users.

Leading companies in the wearable computing industry, e.g. Google, Samsung, and Apple are producing different wearable devices that could have a noticeable impact in education; however, there are some valid reasons behind people not being very enthusiastic to buy them just yet. Such reasons could be the cost, a not eye-catching design, battery lifetime, and the overheating issue. Moreover, wearable devices are almost non-functional without the smart phone being close to them at all times. "Wearable devices from Google, Motorola, and even apple have already been criticized for poor battery life for reason other than GPS support. Recording video would drain Google glass battery pretty quickly" [18]. A number of researchers and educators criticized the high cost of wearable devices. This aspect forms a practical issue, as the prices of wearable devices are much higher than those of smart phones, which makes these devices inaccessible to many students [6]. This is an obstacle facing educational institutions when thinking to consider integrating this technology in learning and teaching activities.

Reference [19] indicated further apprehensions that "the proliferation of wearable devices may also increase concerns about privacy and security of data, dependence on outside vendors for storage and analysis of big data, and access by students of all socioeconomic levels". By using these devices, students are capable of taking photos sneakily and recording videos without permission [6]. There might be some legal issues/consequences involved in the use of wearable technologies in education, e.g. recording informal interactions with the lecturer during the recording of the session then using this recording when issuing a complaint. 
This requires educators and/or academic institutions to have a firm policy to control this [6].

The screen size of wearable devices is another issue facing the extended use of this technology in education. A small display can limit the amount of information shared between educators and their students at any given time. This issue forms an area of concern to many educators and academic organizations. "Wearable display size is small, which may create issues for users to adopt it. $12 \%$ believed that display/interface dimensions are not enough, because it may be hard for the users to read a text from such a small display" [20].

In addition to the above, the possibility of cheating during exams has risen with the introduction of wearable computing in education. Sharing of information, which is greatly facilitated by different wearable devices, some of which could be quite small and/or difficult to recognize, have made exam invigilation harder. Some educators believe that one of the serious negative impacts of wearable technologies in education is their possible use by students to cheat on exams, e.g. recording an online test and sharing it with others [6]. "Recently, some UK universities banned student from wearing watches during examination... The reason that some student can use smart watches to cheat" [18].

\section{CONCLUSION}

Similar to other technologies, the application of wearable computing in education has a number of advantages, but also accompanied by a number of restrictions. Although the degree of individual limitation depends mainly on the type of wearable device and the educational scenario it is applied in, there is a considerable number of different situations, where the application of wearable technologies in learning and teaching results in negative aftereffects.

The various examples contained within this paper could be used efficiently by educators and/or educational institutions to develop the way they implement wearable devices in the education of their students.

\section{REFERENCES}

[1] L. Johnson, S. A. Becker, M. Cummins, V. Estrada, A. Freeman, and C. Hall, NMC Horizon Report: 2016 Higher Education Edition, Austin, Texas: The New Media Consortium, 2016.

[2] B. K. Sandall, "Wearable technology and schools: Where are we and where do we go from here?" Journal of Curriculum, Teaching, Learning and Leadership in Education, vol. 1, no. 1, pp.74-83, May 2016.

[3] T. N. Swathi and S. Lanka, "Wearable technology a new paradigm in Educational Universities," International Journal on Computer Science and Engineering (IJCSE), vol. 7, no. 4, pp. 48-52, April 2015.

[4] M. Bower, D. Sturman, and V. Alvarez, "Perceived utility and feasibility of wearable technologies in higher education," in Proc. 15th World Conference on Mobile and Contextual Learning, mLearn, October 2016, Sydney.

[5] C. Carriere, "The Implications of Wearable Technology in Education," Tophatmonocle Corp., 2017.
[6] D. Sturman and M. Bower, "What are the educational affordances of wearable technologies?" Computers \& Education, vol. 88, pp. 343-353, October 2015.

[7] M. Afshari, "Wearable technology in education," Cloud Tweaks Connecting Our Planet, July 08, 2014.

[8] V. Alvarez, M. Bower, S. D. Freitas, S. Gregory and B. D. Wit, "The use of wearable technologies in Australian universities: Examples from environmental science, cognitive and brain sciences and teacher training," Mobile Learning Futures - Sustaining Quality Research and Practice in Mobile Learning, 15th World Conference on Mobile and Contextual Learning, October 24-26, 2016, pp. 25-32.

[9] R. Sivakumar, "Google glass in education," Conflux Journal of Education, vol. 2, no. 2, pp. 27-30, July 2014.

[10] M. Hussein and C. Nätterdal, "The benefits of virtual reality in education," Department of Computer Science and Engineering, Chalmers University of Technology, University of Gothenburg, Sweden, June 2015.

[11] J. Wylie, "Google expeditions: Lesson ideas \& support for schools," Owlcation - Academia, September 2016.

[12] Google, "What is expeditions?" Expeditions Help, 2017.

[13] B. P. Hyndman, "A simulation pedagogical approach to engaging generalist pre-service teachers in physical education online: The gopro trial 1.0," Australian Journal of Teacher Education, vol. 42, no. 1, pp. 84-102, 2017.

[14] E. Burton, "6 wearable technologies that are most helpful in the classroom," TEACHERCAST, March 2016.

[15] A. Labus, M. Milutinović, D. Stepanić, M. Stevanović, and S. Milinović, "Wearable computing in e-education," Journal of Universal Excellence, no. 1, pp. A39-A51, March 2015.

[16] A. Ezenwoke, O. Ezenwoke, A. Adewumi, and N. Omoregbe, "Wearable technology: Opportunities and challenges for teaching and learning in higher education in developing countries," in Proc. INTED 2016 Conference, 7-9 March 2016, Valencia, Spain, pp. 1872-1979.

[17] J. Macdonald, "A review studying wearable technology and augmented reality as it may apply to teaching and learning," Academia.edu, 2015.

[18] O. Adediwura and O. Joy, "Wearable technology for teaching and learning of concepts in chemistry: Prospect and challenges," Indian Journal of Science, vol. 24, no. 90, pp. 125-133, February, 2017.

[19] A. C. Borthwick, C. L. Anderson, E. S. Finsness, and T. S. Foulger, "Special article personal wearable technologies in education: Value or villain?" Journal of Digital Learning in Teacher Education, vol. 31, no. 3, July 2015.

[20] S. Kumar, "Technological and business perspective of wearable technology," Thesis, Centria University of Applied Sciences, Finland, January 2017.

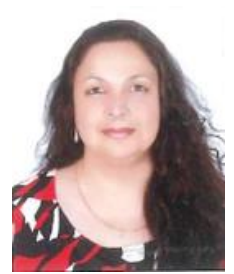

Belsam Attallah is in computer science from the University of the West of England (UWE), UK, a senior fellow of the Higher Education Academy (HEA), UK, and a member of the British Computer Society (BCS), the Chartered Institute for IT, UK. She had seventeen years of experience in the IT industry, and ten years experience in higher education programmes in partnership with the University of Bath and the University of the West of England, UK. Currently, she is an assistant professor, division chair of the Computer Information Science (CIS) Division, Higher Colleges of Technology (HCT), UAE.

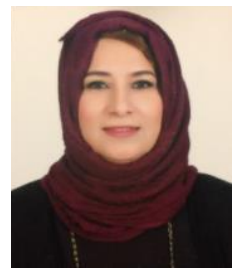

Zakea Il-Agure is in computer science and artificial intelligence from Staffordshire University, UK, the masters in computer science from the University of East Anglia, UK; the masters in research methods from Staffordshire University, UK; the chapter secretary of IEEE in the UAE. She has twenty-three years of experience in lecturing in higher education. She had nine years of experience in the field of machine learning and data mining. Currently, she is an assistant professor in the computer information science (CIS) division, higher colleges of technology (HCT), UAE. 